\title{
Erratum to: Homeowner Attitudes and Practices Towards Residential Landscape Management in Ohio, USA
}

\author{
Thomas W. Blaine • Susan Clayton • \\ Paul Robbins $\cdot$ Parwinder S. Grewal
}

Received: 16 November 2012/ Accepted: 19 November 2012/Published online: 13 December 2012

(C) Springer Science+Business Media New York 2012

\section{Erratum to: Environmental Management}

(2012) 50:257-271

DOI 10.1007/s00267-012-9874-x

The original version of the article entitled "Homeowner attitudes and practices towards residential landscape management in Ohio" (Environmental Management, 2012, 50:257-271) contained two mistakes in Figure 8 and Table 4. The correction should be:
- The vertical axis in Figure 8 should read as "Number of Respondents" instead of "\% Respondents", and the second sentence under the Figure should read as "Data are number of respondents" instead of "percentages of respondents".

- The parameter on Income in Table 4 should be " 0.35 " instead of " -.35 ".

The online version of the original article can be found under doi:10.1007/s00267-012-9874-x.

T. W. Blaine · P. S. Grewal $(\bowtie)$

Urban Landscape Ecology Program, The Ohio State University,

Wooster, OH 44691, USA

e-mail: grewal.4@osu.edu

S. Clayton

Department of Psychology, College of Wooster, Wooster,

OH 44691, USA

\section{P. Robbins}

Department of Geography and Regional Development,

University of Arizona, Harvill Building \#437A, Tucson,

AZ 85721, USA 